* Doutor em Filosofia pela Universidade Federal do Rio de Janeiro (UFRJ). Mestre em Filosofia pela Pontifícia Universidade Católica do Rio Grande do Sul (PUCRS). Graduado em Filosofia pela Universidade de Passo Fundo (UPF). Graduado em Direito pela Faculdade Metropolitana Londrinense (FML). Professor Associado da Universidade Estadual de Londrina (UEL) nos cursos de Filosofia e Direito, atuante na graduação e pósgraduação lato e stricto sensu. E-mail: elve@uel.br.

** Mestre em Direito Negocial (Relações Internacionais) pela Universidade Estadual de Londrina (UEL). Mestre em História Política pela Universidade Estadual de Maringá (UEM). Pósgraduada em Direito do Estado, com ênfase em Direito Constitucional, pela Universidade Estadual de Londrina (UEL). Graduada em História e em Direito pela Universidade Estadual de Londrina (UEL). Professora da Universidade Norte do Paraná (UNOPAR). Email: janainavargastesta (a) gmail.com.

\section{Universalização de direitos trabalhistas: uma proposta de avanço no papel da Organização Internacional do Trabalho}

\author{
UNIVERSALIZATION OF LABOR RIGHTS: A \\ PROPOSAL OF ADVANCE IN THE ROLE OF THE \\ INTERNACIONAL LABOR ORGANIZATION
}

\author{
* Elve Miguel Cenci \\ ** Janaina Vargas Testa
}

Resumo: A presente discussão propõe uma reflexão a respeito da universalização de direitos mínimos trabalhistas no contexto da globalização econômica. Por meio de uma pesquisa bibliográfica e de análise de documentos jurídicos (legislação e tratados internacionais), pretende-se demonstrar que a proteção de certos direitos trabalhistas, com status de direitos humanos, tem sido promovida pela Organização Internacional do Trabalho (OIT). Em que pese tal fato, a fim de permitir a efetividade destes direitos, fazem-se necessários certos avanços no papel da OIT, em seu âmbito interno e em suas relações externas. Os elementos que poderiam representar estes avanços serão demonstrados por meio de alguns apontamentos que, mesmo tendo caráter de provocações, poderão contribuir para a consolidação de uma organização de garantia transnacional mais efetiva na proteção de direitos humanos trabalhistas.

Palavras-chave: Direitos humanos. Direitos trabalhistas. Organização internacional do trabalho.

Abstract: The present discussion proposes a reflection about the universalization of minimum labor rights in the context of the economical globalization. By means of bibliographical research and document analyses (legislation and international treaties), it intends to demonstrate that the protection to certain labor rights, with human rights status, has been promoted by the International Labor Organization (ILO). In spite of this fact, in order to permit the effectiveness of these rights, some advances in the role of the ILO are necessary, in its internal ambit and in its external relations. The elements which could represent this progress will be demonstrated by means of some notes that, even having character of provocations, may contribute to the consolidation of an organization of transnational guarantee which is more effective in the protection of human rights.

Keywords: Human rights. abor rights. International labor organization. 


\section{INTRODUÇÃO}

Hodiernamente, a sociedade mundial assiste a um processo contínuo de avanço tecnológico, informatização da produção e aumento do consumo, fatores que tornam as relações econômicas mais complexas diante da existência de um mercado, cada vez mais, global. Neste contexto, novas formas de relações de trabalho surgem, as quais demandam a criação de novos direitos, bem como a proteção de direitos mínimos já existentes.

O Estado nacional, nesta esteira, contraditoriamente, intervém cada vez menos nas relações negociais, tendo em vista a minimização das economias nacionais e o constante aumento da integração dos mercados. A liberação do comércio internacional, a ausência de regulamentação do mercado e a eliminação de barreiras comerciais resultam na diminuição do papel do Estado nacional na economia e na delegação de suas funções ao setor privado.

Diante desta crise estatal e da falta de regras e limites para o mercado e para as relações negociais, questiona-se: como garantir a dignidade e os direitos fundamentais aplicados às relações de trabalho, se as empresas multinacionais e transnacionais acabam por colocar em concorrência os Estados, ao almejarem a redução de tributos e das garantias aos trabalhadores? Esta é a indagação nuclear do estudo que ora se propõe.

A solução, ao questionamento supracitado, poderia estar na criação de uma instituição de garantia transnacional, conforme propôs Luigi Ferrajoli, voltada para os direitos humanos em substituição e, se necessário for, contra os Estados, que tivesse a possibilidade de promover a universalização de direitos mínimos trabalhistas.

Sabe-se que já existe na sociedade global uma instituição cujo papel é o de tutelar os direitos laborais: a Organização Internacional do Trabalho (OIT). Todavia, este estudo parte do princípio de que esta organização também vive um momento de crise, não possuindo força suficiente e nem legitimidade democrática para responder aos anseios dos trabalhadores nas atuais relações comerciais em nível transnacional.

A ideia, portanto, é apontar elementos, os quais, além de demonstrar que as iniciativas normativas da OIT são insuficientes para as mudanças ocasionadas pela globalização, se direcionam para uma nova feição de organização internacional mais efetiva e humanizadora, aproximando-se, assim, de uma instituição de garantia transnacional promotora de direitos universais trabalhistas. 
Por meio de uma pesquisa bibliográfica e de análise de documentos jurídicos (legislação e tratados internacionais), propõe-se refletir sobre possíveis avanços no papel desta Organização Internacional.

\section{DIREITOS TRABALHISTAS UNIVERSAIS}

Todo trabalhador, por ser humano, possui a qualidade intrínseca da dignidade e é, portanto, merecedor deste reconhecimento, o que implica uma série de proteções que concretizem o respeito a essa dignidade.

Essa necessidade de se garantir direitos mínimos, fundamentais, que concretizem o respeito à dignidade do trabalhador está, inclusive, positivada na Declaração Universal dos Direitos Humanos (ORGANIZAÇÃO DAS NAÇÕES UNIDAS, 1948), ao estabelecer, em seu artigo XXIII, que toda pessoa humana tem direito ao trabalho, à livre escolha do trabalho, a condições equitativas e satisfatórias de trabalho e à proteção contra o desemprego.

Para que o trabalho contemple e promova a dignidade da pessoa humana, deve ser realizado dentro de condições dignas, decentes e saudáveis, de modo a satisfazer o mínimo existencial mencionado por Barroso (2013), no intuito de viabilizar as condições sociais mínimas, ao garantir, ao menos, as necessidades básicas do ser humano que labora.

Se a dignidade da pessoa humana pressupõe a existência de direitos que garantam o mínimo existencial, presume-se que a dignidade do trabalhador somente será concebida se certos direitos trabalhistas tiverem o seu reconhecimento universal como direitos humanos. Logo, se faz necessária a preservação de alguns direitos mínimos a serem preservados globalmente a todo ser humano. Mas, que direitos seriam esses?

Nascimento (2013), ao apresentar os direitos mínimos a serem assegurados a todo trabalhador, manifestou-se no sentido de que o direito do trabalho visa a uma plataforma de direitos básicos do trabalhador, impostergáveis, como o direito a um salário; ao descanso diário, semanal e anual; à proteção da integridade física e saúde com a reparação econômica dos danos que suportar pelo exercício do trabalho.

Delgado (2015, p. 123, grifo nosso), por sua vez, ao defender a ideia de que existem parcelas trabalhistas imantadas por uma tutela de interesse público, por constituírem um patamar civilizatório mínimo que a sociedade democrática não concebe ver reduzido, afirma que: 
[...] esse patamar civilizatório mínimo está dado, essencialmente, por três grupos convergentes de normas trabalhistas heterônomas: as normas constitucionais em geral [...]; as normas de tratados e convenções internacionais vigorantes no plano interno (expressando um patamar civilizatório no próprio mundo ocidental em que se integra o Brasil); as normas legais infraconstitucionais que asseguram patamares de cidadania ao indivíduo que labora (preceitos relativos à saúde e segurança do trabalho, normas concernentes a bases salariais mínimas, normas de identificação profissional, dispositivos antidiscriminatórios, etc.).

Piovesan (2012) e Trindade (2003), ao destacarem a relevância do Pacto Internacional dos Direitos Econômicos, Sociais e Culturais, relatam que o documento enuncia um extenso catálogo de direitos, que inclui o direito ao trabalho e à justa remuneração; o direito a um nível de vida adequado; à participação na vida cultural da comunidade. São direitos que propiciam o desenvolvimento dos indivíduos e consideram a condição humana como fim e abraça a ideia dos direitos sociais, econômicos e culturais, e não dos resultados econômicos em si.

Isto posto, ao tomar por base diversos documentos internacionais ${ }^{1}$, na perspectiva da dignidade da pessoa humana e da ideia de trabalho decente propagada internacionalmente, é possível afirmar que há, atualmente, um rol de direitos do trabalho universalmente reconhecidos, sob o status de direitos humanos: Direito à liberdade de trabalho; Direito à igualdade salarial; Remuneração justa e satisfatória; Direitos sindicais; Direito ao repouso; Condições de trabalho justas e higiennicas; Combate ao trabalho forçado e à escravidão; Proibição do trabalho infantil; Combate à discriminação no trabalho; Proteção em face dos riscos sociais; Proteção contra o desemprego.

Destarte, esses seriam os direitos a garantir um padrão mínimo civilizatório universal ao trabalhador. Sem dúvida que outros poderão ser agregados, acrescidos ao rol, de modo a criar uma proteção contínua e progressiva a quem labora. O fato é que, com fundamento em documentos internacionais, nenhuma comunidade/Estado/nação poderá se esquivar de garantir tais direitos, tendo em vista que todos os Estados-membros da Organização das Nações Unidas (ONU) e da OIT são signatários da Declaração Universal dos Direitos

\footnotetext{
Declaração Universal dos Direitos (ORGANIZAÇÃO DAS NAÇÕES UNIDAS, 1948); do Pacto de Direitos Econômicos, Sociais e Culturais (PIDESC, 1966); do Ato Constitutivo da OIT (ORGANIZAÇÃO INTERNACIONAL DO TRABALHO, 1946) e de sua Declaração Relativa aos Direitos e Princípios Fundamentais do Trabalho, adotada em 1998.
} 
(ORGANIZAÇÃO DAS NAÇÕES UNIDAS, 1948); do Pacto de Direitos Econômicos, Sociais e Culturais (PIDESC, 1966); do Ato Constitutivo da OIT (ORGANIZAÇÃO INTERNACIONAL DO TRABALHO, 1946) e de sua Declaração Relativa aos Direitos e Princípios Fundamentais do Trabalho, adotada em 1998.

Infere-se, por meio da leitura dos textos internacionais, que não é qualquer tipo de trabalho que poderá manter a dignificação do homem, mas somente o prestado em condições adequadas e justas, capaz de proporcionar um padrão de vida que assegure o mínimo bem estar: alimentação, vestuário, moradia, saúde e serviços sociais frente a algumas contingências, como no caso de desemprego, invalidez, doença, velhice (ORGANIZAÇÃO DAS NAÇÕES UNIDAS, 1948).

Verificam-se, também, na própria ideia de trabalho decente propagada pela OIT, os fundamentos da proteção universal de direitos do trabalho, ao pregar a liberdade de associação e o reconhecimento do direito de negociação coletiva; a eliminação de todas as formas de trabalho forçado ou obrigatório; a abolição efetiva do trabalho infantil e a eliminação da discriminação em matéria de emprego e de profissão (ORGANIZAÇÃO INTERNACIONAL DO TRABALHO, 1998).

O direito ao trabalho, diante seu caráter social, exige do Estado e dos particulares, uma posição ativa no sentido de prevalecer este direito. Nesta perspectiva, a padronização mínima de suas regras não pode e não deve estar a serviço da liberdade absoluta do mercado, por servir à própria saúde da concorrência do comércio, ao não permitir que a ausência de standards (padrões) universais transforme o trabalho em mera mercadoria, o que pode levar a coisificação do trabalhador.

Nas palavras de Mahnkopf (2005, p. 68):

Deve-se, genericamente, concentrar todos os esforços para que os core labour standards da OIT sejam implementados no mundo inteiro. Isso somente será possível se os padrões trabalhistas e sociais forem compreendidos como elementos centrais da luta pelos direitos humanos de segunda e terceira geração e do combate de formas modernas de trabalho forçado e trabalho escravo.

Assim, conclui-se que há direitos0 mínimos universais prescritos em normas internacionais, a serem aplicados a todo o trabalhador em nível global, 
ao encontro da preservação do valor fundamental - dignidade da pessoa humana - e da ideia de trabalho decente. Podem ser chamados de direitos transnacionais porque não encontram fronteiras para a sua aplicação. Logo, infere-se que há, atualmente, um direito do trabalho global responsável pela garantia de mínimo existencial civilizatório ou, nas palavras de Moreira (2010), o mínimo existencial segundo o parâmetro global.

Importante frisar que o núcleo de direitos deve ser gradativamente ampliado, em esforço conjunto de todas as nações, acrescentando aqueles que se revelam essenciais para a concretização do trabalho decente e da dignidade do trabalhador.

Feitas estas conclusões, o questionamento que ainda persiste se refere à existência ou não de um órgão responsável não apenas em criar esta normativa, mas também de fiscalizar a efetividade das normas, bem como em julgar e punir no caso de violação.

Afinal, não basta a existência de direitos trabalhistas mínimos universais, aqui elencados, fazendo-se necessária a existência de uma Organização apta a efetivar esta proteção.

\section{PARA ALÉM DE UMA ORGANIZAÇÃO INTERNACIONAL DO TRABALHO: POR UMA INSTITUIÇÃO TRANSNA- CIONAL GARANTIDORA DE DIREITOS UNIVERSAIS DO TRABALHO}

A presente discussão tem início com a constatação realizada por Faria (2010, p. 160), ao analisar os direitos humanos à luz da globalização econômica: "[...] a universalização e a efetivação dos direitos humanos vivem hoje uma situação paradoxal - quanto mais são afirmados, mais são negados e [...] abremse para o século 21 como uma interrogação, jamais como certeza".

Justamente pela intenção de mudar essa realidade é que se pretende apresentar, a seguir, uma possível proposta, talvez audaciosa ou utópica, de uma instituição de garantia promotora de direitos universais aplicados às relações de trabalho. Esclarece-se, no entanto, que a pretensão se limita apenas à apresentação de alguns apontamentos que poderão contribuir para o desenvolvimento da proteção de direitos humanos trabalhistas.

AOIT, sem dúvida alguma, tem promovido um importante e imprescindível papel na proteção de direitos trabalhistas no campo mundial. 
Não obstante a significativa atuação da OIT, torna-se possível inferir que a Organização tem vivido uma crise institucional, que para Crivelli (2010, p. 200) representa uma crise que redundou na sua capacidade jurídica e institucional de fazer frente aos novos fatos econômicos e sociais.

A crise acima aludida está associada a uma disfunção do modelo jurídico adotado pela OIT em relação à nova realidade econômica e social. Neste contexto, a seguir, serão realizados alguns apontamentos que poderão servir de elementos a promover o desenvolvimento da Organização, no sentido de aproximá-la de uma instituição de garantia, conforme propôs Luigi Ferrajoli (2005).

Cumpre esclarecer que tais apontamentos são apresentados mais como provocações do que como soluções. Afinal, este ensaio não tem a pretensão de resolver um problema tão complexo e importante do ponto de vista social, e sim o de contribuir para uma reflexão.

A ideia é pensar acerca da possibilidade de uma Organização Internacional do Trabalho cujas características sejam a obrigatoriedade, a universalidade e a desburocratização.

Todos os apontamentos representam uma proposta de melhoria da OIT, com o intuito de permitir que este órgão seja capaz de lidar com os efeitos prejudiciais da globalização econômica nas questões sociais, representando uma instituição transnacional, apta a regulamentar, fiscalizar e efetivar normas universais em matéria trabalhista; por meio de sistema de controle, monitoramento e acesso democrático, direcionado a limitar a celebração do negócio jurídico nas relações jurídicas laborais de caráter transnacional.

\subsection{Primeiro Apontamento: a Representação Tripartite}

O primeiro apontamento a ser feito colocaria em pauta a questão da representação tripartite presente nos órgãos da OIT. A ideia não é extinguir o tripartismo, mas demonstrar que o sistema merece adequações.

É preciso considerar que a OIT, segundo Jeammaud (2000), além de ter sido constituída por meio de uma reivindicação do patronato e não dos trabalhadores, contém problemas de estrutura porque estabelece o dobro de representante dos Estados nacionais em detrimento da representação de empregadores e empregados, o que leva a inferir que a Organização não apresenta uma representação paritária, ao revelar um fator antidemocrático.

Crivelli (2010) também apresentou uma crítica à definição da composição e poderes na Conferência Geral da OIT, ao constituir um tripartismo não paritário, 
adotando a representação governamental com dois votos, e as representações de trabalhadores e empregadores com um voto cada uma.

Ferrajoli (2005) estabelece que os órgãos internacionais de proteção de direitos humanos devem atuar, se necessário for, contra os Estados. Essa realidade jamais se concretizaria simplesmente porque os Estados estão representados na Conferência Internacional da $\mathrm{OIT}^{2}$ e no Conselho de Administração ${ }^{3}$ duas vezes mais em relação aos empregados e empregadores, e possuem peso maior na votação de convenções, recomendações e decisões acerca do recebimento de queixas e reclamações.

Parece nítido que há um problema de legitimação na estrutura tripartite porque falta uma fundamentação plausível que possa justificar a maior representação pelos governos dos Estados. Se a pretensão, hodiernamente, é "derrubar" a dicotomia direito nacional versus direito internacional, no sentido de desenvolver a criação de um único ordenamento que possa proteger direitos trabalhistas mínimos universais, sob a concepção de que os direitos humanos prevalecem sobre os interesses estatais, torna-se lógico concluir que o sistema

\footnotetext{
2 A Conferência Internacional (CIT) é o órgão de cúpula da OIT, conhecida também por Conferência Geral. É formada por representantes dos Estados-membros e realiza sessões, ao menos, uma vez por ano em Genebra, às quais comparecem os representantes, embora possa haver reuniões extraordinárias quando necessário. A CIT tem competência para delinear as diretrizes gerais das políticas e das ações da OIT, sendo o órgão no qual os Estados-membros da entidade negociam as normas e elaboram convenções e recomendações, aprovadas por dois terços dos votos dos delegados presentes. A Conferência Geral também é responsável por questões administrativas, tais como orçamento, admissão de novos membros; e tem poderes para deliberar acerca de sua competência, por meio de resoluções, aprovadas pela maioria simples dos votos dos presentes e respeitado o quórum mínimo de metade dos delegados que compõe a OIT. Para atender à composição tripartite, cada Estadomembro é representado por quatro delegados, sendo dois designados pelos governos, um pelos empregadores e outro pelos trabalhadores.

3 Conselho de Administração é o órgão executivo da OIT cuja função é exercer a administração da Organização, sendo composta também de membros do Governo, trabalhadores e empregadores representantes dos países de maior importância industrial. Reúnem-se três vezes por ano, em Genebra. É formado por 56 titulares, sendo 28 representantes de Estados, 14 de empregadores e 14 de empregados, eleitos para mandatos de três anos por colégios eleitorais constituídos pelos delegados dos grupos participantes da CIT. Dentre os representantes governamentais, dez são nomeados pelos Estados-membros de "maior importância industrial", conforme disposto na Constituição da OIT. Atualmente, os dez Estados-membros de maior importância industrial são Alemanha, Brasil, China, Estados Unidos, França, Índia, Itália, Japão, Reino Unido e Rússia. Dentre as diversas competências do Conselho de Administração, destacam-se: a tomada de decisões sobre as políticas da OIT; a deliberação sobre as datas de reuniões da CIT; a designação dos 10 Estados de maior importância industrial; a eleição do Diretor-Geral da RIT; a instituição de comissões permanentes ou especiais; a deliberação sobre os relatórios e conclusões de seus próprios órgãos internos, como o Comitê de Liberdade Sindical; a fiscalização do cumprimento das obrigações dos Estados signatários das convenções da OIT; a adoção de medidas em caso de reclamação ou queixa contra um Estadomembro por inobservância de instrumento que tenha ratificado, tais como a edição de recomendações ou a suspensão de medidas executórias contra Estados que violaram a legislação internacional do trabalho.
} 
tripartite da OIT deveria privilegiar a representação dos trabalhadores e empregadores, e não dos Estados nacionais.

Ademais, no momento em que a OIT foi criada, justificava-se a representação estatal em quantidade superior à representação de empregados e empregadores, simplesmente porque havia a concepção de que apenas Estados seriam sujeitos de direito internacional. Esta tese, atualmente, não mais se sustenta, tendo em vista que se pretende elevar o indivíduo - o trabalhador - a sujeito de direito internacional. Logo, o sistema tripartite deveria se pautar em uma relação paritária, isto é, em quantidade equânime de governo-trabalhadorempregador.

Essa relação paritária criaria uma base legitimadora à OIT no que se refere à representação de todos os interessados, ao construir uma política que leve em conta, prioritariamente, o interesse dos dois grandes sujeitos da relação de trabalho: trabalhadores e empregadores. É preciso também tornar transparente os processos decisórios e os atos da OIT, pois a simples transferência da competência do Estado nacional para uma organização internacional leva a um vazio de legitimação.

Isso poderia ser atenuado, por exemplo, com a participação dos trabalhadores, no âmbito dos Estados nacionais, na escolha de sua representação na OIT, o que poderia ser feito mediante a apresentação de listas de nomes pelas organizações profissionais, a fim de permitir a participação na escolha dos delegados.

\subsection{Segundo Apontamento: o Diálogo Social}

$\mathrm{O}$ segundo apontamento que merece ser apresentando se refere a medidas para o avanço do diálogo social ${ }^{4}$. Isso poderia ocorrer por meio de duas propostas: fortalecimento da representatividade sindical e o aumento da participação dos empregados na gestão da empresa. Tais providências poderiam ser tomadas como políticas de prioridade da Organização junto aos Estadosmembros.

Em relação à primeira medida, qual seja, o fortalecimento da representatividade sindical, cumpre ressaltar que se trata de medida urgente a robustecer o diálogo social. Ericson Crivelli (2010, p. 230) teria, neste sentido,

\footnotetext{
${ }^{4}$ O Diálogo social é o quarto objetivo estratégico da promoção de trabalho decente lançada pela OIT. O diálogo social deve permitir que as normas, as políticas públicas e os programas sociais estejam direcionados para as atividades laborais e sejam construídos democraticamente por meio do debate tripartite - entre o governo, os trabalhadores e os empregadores; ou pelo debate bipartite, entre os Parceiros Sociais (sindicatos) e as organizações dos empregadores.
} 
observado que "[...] se é certo que os sindicatos estão em declínio, também é certo que o modelo de diálogo social, uma das bases sobre as quais se assentou o direito internacional do trabalho, está seriamente ameaçado".

Por isso, um avanço importante seria a formação de sindicatos representativos de trabalhadores de empresas multinacionais e/ou transnacionais, como tem ocorrido, por exemplo, na Europa (NASCIMENTO, 2013, p. 459):

O traço maior do direito sindical contemporâneo é a sua tendência expansiva territorial na União Europeia onde se estendeu em âmbito comunitário com a criação de entidades sindicais que representam trabalhadores de mais de um país. Na Europa, há sindicatos de trabalhadores de empresas multinacionais.

A formação de um sindicato nos moldes acima citados, que poderia ser criado por setores ou regiões, permitiria também o fortalecimento de negociações coletivas, que poderiam estatuir sobre determinados direitos, atendendo às especificidades de uma determinada região ou de um determinado setor da economia, com base nas diretrizes traçadas pela OIT, a serem seguidas pelas empresas multi/transnacionais. Assim, a Organização também teria que criar programas de conscientização nos Estados-membros ou em regiões abrangidas por Blocos econômicos, bem como estabelecer instruções básicas a serem respeitadas na geração de entidades sindicais nestes termos.

Sabe-se que a convenção coletiva é norma jurídica, pois norma não é, unicamente, um ato estatal. Deste modo, a convenção coletiva, por ser exemplo de norma privada, é expressão do pluralismo jurídico, isto é, a teoria segundo a qual a produção do direito positivo é estatal e não estatal.

A OIT, por meio das Convenções n. 98 e 154, incentiva a prática da negociação coletiva por considerá-la a melhor forma de composição dos interesses nas relações de trabalho. O Comitê de Liberdade Sindical da Organização Internacional do Trabalho, órgão que aprecia reclamações de sindicatos sobre eventual violação da liberdade sindical no país, considera o direito de negociar, segundo Nascimento, elemento essencial da liberdade sindical, por isso torna-se imprescindível o comportamento da boa-fé pelas partes negociantes, como meio de inspiração da mútua confiança, necessário para o êxito da negociação (NASCIMENTO, 2013, p. 502):

Quanto às relações entre os diferentes níveis de negociação há modelos de negociação articulada, como a Itália, inter-relacionando-se os 
contratos coletivos das centrais sindicais e os acordos coletivos de categoria e empresa, de modo que os primeiros estabelecem parâmetros máximos e mínimos que devem ser observados por estes, espécie de negócio jurídico coligado, iterativo, e há o modelo de negociação desvinculada, como no Brasil, sendo independentes as convenções e os acordos coletivos, hierarquicamente aplicável à cláusula mais favorável ao trabalhador na comparação entre as que foram em ambos fixadas (CLT, art. 620). (grifo do autor)

Obviamente que as negociações coletivas não poderiam criar direitos menos favoráveis aos trabalhadores e deveriam respeitar não somente os direitos previstos nas legislações nacionais/locais, mas também as normas da OIT, o que poderia ser realizado por meio da negociação articulada.

Além da Organização Internacional do Trabalho criar políticas em prol da criação de sindicatos representativos de empresas transnacionais e de incentivar a negociação coletiva, a OIT precisaria também trabalhar em prol da ratificação e efetividade da Convenção $n^{\circ} 87$. Esta Convenção assegura a liberdade dos trabalhadores de selecionar o sindicato que melhor os representa, com base no princípio da pluralidade sindical, que permite a existência de diversos sindicatos representando a mesma categoria em uma mesma base territorial.

A pluralidade sindical é importante porque contribui para a consolidação da representatividade que consiste na efetiva capacidade do sindicato em ser o porta-voz dos seus representados, o que depende da legitimidade da organização sindical e de sua força de mobilização.

O Brasil, juntamente com os Estados Unidos, Índia, China e Irã, não assinaram a Convenção $n^{\circ} 87$, e tais países representam grande parte da mão de obra do mundo. Esse fato compromete consideravelmente a efetividade desse instrumento. A omissão destes países contribui para o enfraquecimento de um dos pilares sobre os quais se erige a estrutura da OIT: a liberdade sindical, interferindo na consolidação do diálogo social.

Logo, se faz urgente a adoção de medidas, dirigidas pela OIT, no sentido de efetivar a Convenção $n^{\circ} 87$.

A segunda medida a fortalecer o diálogo social seria a criação de programas junto aos Estados-membros que pudessem assegurar a participação dos trabalhadores na gestão das empresas. O trabalhador é, sem dúvida alguma, o ator social principal da atividade econômica e, contraditoriamente, o que menos possui poder de negociação nas relações de trabalho. 
Além de proporcionar o exercício da transparência da gestão empresarial, o direito à participação na gestão da empresa possibilitaria uma maior motivação laboral, que resultaria na cooperação pelo desenvolvimento das atividades empresariais.

Particularmente, no Brasil, a Constituição de 1988 previu esse direito no art. $7^{\circ}$, inciso XI, mas pelo fato da norma exigir lei regulamentadora, a ausência desta tem impedido o exercício e a aplicabilidade do dispositivo constitucional. Em que pese tal fato, alguns tratados internacionais têm previsto tal direito, bem como a legislação de certos países.

Sobre a temática, Arnaldo Süssekind (2004) explica que a Constituição de Weimar, na Alemanha, em 1919, foi a primeira a prescrever a criação de conselho de trabalhadores nas administrações das empresas. Mais tarde, em 1976, a Alemanha regulamentou o assunto mediante a lei de co-gestão dos assalariados, constituindo conselhos compostos de representantes dos acionistas e dos empregados, em igual número e com poderes de decisão.

Em sua Constituição Federal de 1958, a França previu o sistema de representação dos trabalhadores na gestão das empresas por meio de delegados. Mais tarde, uma lei do país de 1948 dispôs que (SÜSSEKIND, 2004, p. 213214):

O Comitê de empresa determina que as empresas com mais de 50 empregados deve compor um comitê com um diretor, 2 a 11 trabalhadores eleitos, um representante dos sindicatos interessados (sem direito a voto) e um do serviço social da empresa. Este comitê opina em matéria econômica e financeira.

Arnaldo Süssekind (2004) explica que, a partir de 1970, o direito de participação na gestão da empresa foi previsto também nas Constituições de Portugal (1976), Equador (1978) e Peru (1979).

No âmbito internacional, as Convenções $\mathrm{n}^{\mathrm{o}}$ 135, 148, 155 e 158, da Organização Internacional do Trabalho, bem como as Recomendações $\mathrm{n}^{\circ}$ 84, 94, 119, 129, 130, 137, 163 e 166 da mesma organização dispõem acerca da possibilidade da participação (NASCIMENTO, 2013).

A Convenção no 158 , por exemplo, em seu art. 13, § 1, alínea “a”, estatuiu acerca do direito a consultas de trabalhadores e de suas entidades representativas no término da relação do trabalho, que apenas poderia ocorrer por motivos econômicos, tecnológicos, estruturais ou análogos. Tais consultas seriam necessárias principalmente nas despedidas coletivas. A Convenção impõe, ainda, 
a obrigatoriedade da informação não apenas ao sindicado, mas também às autoridades públicas competentes com o fim de inspecionar a legitimidade e a veracidade da situação informada na empresa (art. 14, Convenção 158) (ORGANIZAÇÃO INTERNACIONAL DO TRABALHO, 1985).

Apenas para fins elucidativos, imperioso frisar que o Brasil, embora tenha assinado e ratificado a Convenção 158 da OIT, o país a denunciou em novembro de 1996. A Constituição de 1988 previu a obrigatoriedade da justificativa da dispensa sem justa causa, em seu art. $7^{\circ}$, inciso I, porém exigiu a regulamentação mediante lei complementar, ainda não concluída no país. Tal situação consolidou a prática de que a dissolução do pacto laboral ficaria sujeita ao arbítrio patronal (LIMA NETO, 2003), constituindo no Brasil a chamada "denúncia vazia do contrato", nas palavras de Delgado (2015).

A título de exemplo, cumpre destacar que a União Europeia, por meio da Diretiva n. 94/45/CE do Conselho, obriga, nas empresas com pelos menos 1.000 trabalhadores e que tenham pelo menos duas filiais em dois Estados-membros da União Europeia, ocupando cada qual, no mínimo, 150 trabalhadores, a constituição de uma Comissão de representação dos trabalhadores (NASCIMENTO, 2013, p. 148):

É digna de realce a criação de novas formas de representação dos trabalhadores em empresas da União Europeia. É um meio de abrir um canal de diálogo entre os trabalhadores e suas empresas transnacionais, assim consideradas as que se instalaram em mais de um país do território europeu comunitário.

Infere-se, portanto, que a OIT poderia, com base na regulamentação já existente por meio de suas Convenções, que seriam utilizados como base, criar programas nos Estados, estabelecendo metas para o concretização do direito dos trabalhadores na gestão da empresa. Tal medida seria importante para a inserção do trabalhador nas negociações laborais, além de contribuir com o fortalecimento da legitimidade da Organização, por meio da efetividade de suas convenções.

\subsection{Terceiro Apontamento: Poder Sancionatório, de Controle e Monitoramento}

$\mathrm{O}$ terceiro apontamento que se faz premente diz respeito à ausência de imposição de sanções e penalidades por parte da OIT, no caso de violação de suas normas, e de seu procedimento de queixas e reclamações. 
O campo de ação da OIT está restrito a um sistema de relatórios e denúncias à comunidade internacional sem a existência de um sistema repressivo ou um tribunal que julgue as violações a direitos trabalhistas cometidos no âmbito dos Estados nacionais. Tal fato, sem dúvida, coopera para a mitigação da atuação dessa Organização, debilitando a fiscalização junto aos entes nacionais que desprestigiam os direitos sociais trabalhistas.

Valério Mazzuoli (2013a), neste sentido, salienta que a falta de enforcement powers da OIT é um fator limitante para a eficácia dos direitos trabalhistas em âmbito internacional, e sugere a necessidade de dotá-la de um sistema sancionatório mais efetivo, voltado simultaneamente para a consecução de objetivos éticos no domínio dos valores e para a repressão das infrações aos direitos trabalhistas enquanto direitos humanos. "[...] [a consolidação] no plano multilateral é deixar à OIT a competência para lidar com a violação dos direitos trabalhistas, aprimorando-se os mecanismos de implementação das decisões adotadas" (AMARAL JÚNIOR, 1999, p. 139-40).

A única possibilidade, hoje, de estabelecer sanções em matéria de direitos trabalhistas seria por meio da Corte Internacional de Justiça ${ }^{5}$, quando uma queixa ${ }^{6}$ promovida por um Estado-membro em face de outro Estado chega à Corte. Entretanto, tal possibilidade é raríssima e de pouca efetividade, já que as queixas é um procedimento raro na OIT.

No que se refere às reclamações ${ }^{7}$, promovidas por organizações sindicais de caráter nacional, não há como impor nenhuma penalização. A Comissão de Peritos $^{8}$ e o Comitê de Liberdade Sindical ${ }^{9}$, por exemplo, procuram por meio do

\footnotetext{
5 A Corte Internacional de Justiça é o principal órgão das Nações Unidas para o tratamento das questões legais, e possui função jurisdicional e consultiva. Apenas Estados podem submeter casos à Corte, não sendo estendida tal possibilidade aos indivíduos.

${ }^{6}$ Uma das espécies de monitoramento e controlado exercido pela OIT é feita mediante queixa. A queixa se trata de um procedimento formal, seu uso é menos frequente e está prevista nos artigos 26 a 34 da Constituição da OIT. A queixa é apresentada por um Estado-membro contra outro Estadomembro, por descumprimento de uma convenção que ambos tenham ratificado. Pode, ainda, ser apresentada de ofício pelo Conselho de Administração ou um por um delegado da Conferência Internacional. O Conselho de Administração assegurará aos Estados o direito de defesa e poderá constituir uma Comissão de Inquérito para examinar a questão, cuja função é apresentar suas conclusões e recomendações ao Conselho. O procedimento de análise das queixas é visto como a única espécie de exercício de jurisdição, uma vez que há a possibilidade de o Estado levar o caso à Corte Internacional. Porém, tal procedimento é praticamente inexistente no âmbito da OIT.

7 As reclamações são mecanismos de controle e monitoramento por parte da OIT. Destinam-se especialmente às organizações de empregadores e de trabalhadores contra qualquer Estado-membro, sob a alegação de descumprimento de uma convenção internacional ratificada. Após recebidas e comunicadas ao governo interessado, as reclamações são transmitidas à mesa do trabalhos do Conselho de Administração que decidirá pela admissão ou não da reclamação. Caso a admita, o Conselho irá constituir uma comissão tripartite para análise do caso. No processo de análise da
} 
diálogo, demonstrar aos Estados que sua prática está em desconformidade com

a norma internacional e tentam convencê-los a corrigir a situação. Entretanto, tais medidas não são eficazes.

A Comissão de Peritos, responsável por analisar as reclamações e emitir relatório sobre elas, não é um órgão jurisdicional, ainda que suas atividades tenham semelhanças com as desenvolvidas pelo Judiciário, já que aplica a norma jurídica ao caso concreto, colhe dados e realiza inspeções. Não obstante tal fato, a Comissão não tem a competência para julgar os casos que aprecia, mas tão somente registrar os casos de infrações e encaminhá-las à Conferência Geral da OIT.

Por isso, se o diálogo com o Estado violador não surtir efeitos, o caminho seria o de apenas estabelecer certa coação moral, por meio da apresentação e discussão do caso na Conferência Geral, com a exposição da situação perante todos os outros Estados-membros da OIT. Destarte, essa falta de imposição de sanções da OIT tem enfraquecido o papel da Organização.

Melhorar, porquanto, a atuação dos órgãos de controle da OIT, revestindoas de poder jurisdicional poderia contribuir para a efetividade das convenções e para a consagração de uma jurisprudência em matéria de direitos trabalhistas universais.

Outro fator importante a destacar seria o de permitir que associações de trabalhadores, organizações não governamentais e o próprio trabalhador individualmente pudessem apresentar reclamações junto à Organização. A

reclamação, vários procedimentos poderão ser adotados, tais como a solicitação de informações à organização reclamante e ao Estado reclamado; poderá também enviar um representante da OIT ao país a fim de colher dados.

8 A Comissão de Peritos é órgão também permanente da OIT, formada por vinte membros de nacionalidades diferentes e de diversas regiões do mundo, eleitos pelo Conselho de Administração, por proposta do Diretor-Geral da RIT, para um mandado de três anos, com direito a recondução, responsável por elaborar relatórios técnicos a respeito da observância das convenções da OIT pelos Estados-membro. Os integrantes da Comissão são personalidades imparciais e independentes, sem vínculos com organizações profissionais ou com qualquer Estado e com experiência em questões de política social e de legislação trabalhista. Esta Comissão de Peritos é responsável também por analisar os relatórios elaborados pelas missões enviadas aos Estados quando investigadas no caso de queixas e reclamações. Importante informar que o relatório da Comissão de Peritos é um documento de natureza jurídica, em que são ressaltados os aspectos jurídicos e fáticos sobre os quais se requer a aplicação efetiva de uma determinada convenção, mas isso não significa que tenham natureza jurídica de decisão judicial. As funções da Comissão de Peritos podem ser classificadas como "quase judiciárias", já que ela não atua como um tribunal.

9 O Comitê de Liberdade Sindical, criado em 1951, se ocupa efetivamente de questões sindicais na OIT. O Comitê tem composição tripartite de nove membros indicados pelo Conselho de Administração entre seus membros titulares. Admitem-se, pelo Comitê de Liberdade Sindical, reclamações de organizações sindicais em face de Estados que violam as Convenções da OIT atinentes às questões de liberdade sindical e negociação coletiva. 
medida se faz urgente para que o trabalhador se torne sujeito de direito internacional.

É preciso lembrar, a título de exemplo, que o Tribunal Penal Internacional julga indivíduos (que é sujeito de direitos e obrigações internacionais); que a Corte Europeia de Direitos Humanos recebe queixas individuais, bem como a Corte Interamericana de Direitos Humanos, ainda que de forma indireta. Isso sem falar de alguns Comitês previstos nos tratados da ONU, tal como o Comitê do Pacto Internacional de Direitos Civis e Políticos. Logo, a OIT também precisa avançar neste sentido.

Afinal, as normas produzidas pela OIT são destinadas ao trabalhador, então, a legitimidade democrática desta Organização pressupõe a possibilidade de acesso direto deste, por meio de apresentação de reclamações individuais.

\subsection{Quarto Apontamento: a Cláusula Social e o Selo Social}

O quarto apontamento, a seguir aduzido, faz alusão a duas propostas já lançadas à comunidade internacional: a adoção da cláusula social e do selo social.

A proposta pela adoção de uma cláusula social nos contratos comerciais internacionais ocorreu mediante uma parceria da Organização Mundial de Comércio (OMC) e da OIT, com vistas a estabelecer como condição prévia dos acordos o estabelecimento de cláusulas que versem sobre padrões trabalhistas mínimos. O tema da cláusula social é diretamente relacionado com o dumping social, visando ao seu combate, ao permitir a aplicação de medidas como salvaguardas e sanções comerciais em geral.

A prática do dumping social representa uma forma de concorrência desleal, além de redundar frequentemente em violação dos direitos fundamentais dos trabalhadores. Assim, a cláusula extrapolaria o significado de mero compromisso moral, tão frequente em declarações de cunho internacional: ela autoriza os países membros da $\mathrm{OMC}$ a apreciar se houve respeito à cláusula $\mathrm{e}$, se for o caso, a adotar as medidas convenientes (ROMITA, 2013).

Entretanto, referida proposta tem servido de críticas por entender, primeiramente, que a OMC não teria a competência de exigir o cumprimento de normas trabalhistas e, segundo, pelo fato da medida ser usada, muitas vezes, para medidas protecionistas (MAZZUOLI, 2013a).

Romita (2013) esclarece que a cláusula social apresenta caráter ambivalente, porque, se de um lado representa uma garantia de jogo limpo em tema de comércio internacional, por outro lado pode mascarar um neocolonialismo baseado em práticas protecionistas. 
Em que pese a proposta não seja ruim, ela pode, indiretamente, comprometer, ainda mais, o papel da OIT. Transferir para a OMC a função de fiscalizar o cumprimento de normas trabalhistas, sob pena de sanções comerciais, debilita a Organização trabalhista, pois intensifica a ausência de seu poder sancionatório. O caminho deveria ser o de atribuir à OIT o poder de penalizar os Estados que violam direitos trabalhistas mínimos e não repassar essa competência à OMC.

Isso não significa que a OMC deve simplesmente abandonar a instituição da cláusula social, mas sim atuar juntamente com a OIT, transferindo a esta a responsabilidade pelas sanções no caso de violação de normas trabalhistas.

Aliás, a falta de poder sancionatório da OIT representou uma das causas principais que levaram os Estados Unidos e diversos outros países desenvolvidos a considerarem a Organização Internacional do Trabalho foro inadequado para o tratamento da cláusula social (MAZZUOLI, 2013a).

A solução parece estar no trabalho conjunto das duas Organizações, delegando à $\mathrm{OMC}$ o papel de fiscalizar o cumprimento da cláusula, tendo em vista que se insere nos contratos comerciais; e à OIT a função de estabelecer o conteúdo da cláusula e a aplicação de punições em caso de descumprimento.

Por sua vez, o selo social poderia servir de alternativa à cláusula social como uma medida a ser adotada pela OIT por meio de políticas e programas perante os seus Estados-membros. O selo social consistiria na fixação de um sinal ou etiqueta em produtos industrializados destinados à exportação, mostrando ao consumidor que o Estado, onde foram fabricados, respeitou as normas internacionais de proteção ao trabalho (MAZZUOLI, 2013a).

Esse selo, também conhecido como "etiqueta social", foi objeto de proposta do ex- Diretor-Geral da OIT, Michel Hansenne, em 1998, e consistiria, para Beltran (1998), num sistema de marcas que deveriam ser estampadas nas embalagens de produtos destinados à exportação como comprovação de que tais mercadorias foram produzidas em consonância com padrões trabalhistas mínimos.

Obviamente que tal medida exigiria um comprometimento por parte das empresas e, principalmente, dos consumidores, ao criarem a consciência de optar por produtos com o selo.

A "etiqueta social", portanto, poderia ser conferida por escritórios da OIT ou por meio de parcerias desta Organização com entidades empresariais, Organizações não governamentais, etc. Um exemplo de certificação dessa modalidade é o selo UNICEF, ao conferir a municípios brasileiros que 
empreendam determinados esforços para a melhoria na qualidade de vida de crianças e adolescentes.

O selo social, então, seria a certificação emitida pela OIT aos produtos/ serviços exportados que atenderam os padrões mínimos trabalhistas proclamados pela Organização.

\subsection{Quinto Apontamento: a Propagação de Princípios do Direito Internacional}

$\mathrm{O}$ quinto e último apontamento destina-se à proposta de propagar e difundir, por parte da OIT, alguns princípios jurídicos do direito internacional, na intenção de torná-los obrigatórios a todos os Estados-membros.

O primeiro princípio se refere à aplicação da norma mais favorável ao trabalhador - pro homine - e da proibição do retrocesso social.

Particularmente, no caso brasileiro, na intenção de avançar na efetividade de um direito do trabalho global, o país precisaria abandonar a tese de supralegalidade $^{10}$ dos tratados de direitos humanos. Esta tese, pacificamente adotada pela jurisprudência brasileira, quando o tratado não é aprovado pelo Congresso Nacional nos termos do quórum estabelecido pelo $\S 3^{\circ}$ do art. $5^{\circ}$ da $\mathrm{CF} / 1988$, apenas enfraquece a proteção dos direitos humanos.

Ora, é preciso lembrar que a Constituição Federal brasileira de 1988, ao arrolar as espécies normativas em seu artigo 59, não previu a espécie "supralegalidade", de tal forma que inexiste na ordem jurídica constitucional brasileira esse status jurídico. Na realidade, o STF, ao prever a supralegalidade acabou, inconscientemente, consagrando a tese de que os tratados internacionais sobre direitos humanos possuem natureza constitucional, sejam na forma do $\S$ $2^{\circ}$ ou $\S 3^{\circ}$ do art. $5^{\circ}$ da Constituição (TESTA; CENCI, 2014).

Ora, se nenhuma legislação infraconstitucional pode derrogar os tratados de direitos humanos, nem mesmo suprimir a sua eficácia; e se, ainda, nenhuma lei pode alterar ou negar vigência aos tratados, a única conclusão plausível é a de que as normas supralegais são, na verdade, constitucionais. Neste sentido, o posicionamento de Feliciano de Carvalho (2013, p. 149), ao afirmar que o STF, ao copiar a teoria da supralegalidade de outros países, constitucionalizou todos os tratados sobre direitos humanos:

\footnotetext{
${ }^{10}$ A supralegalidade se refere à tese de que os tratados e convenções de direitos humanos não podem afrontar a supremacia da Constituição, mas teriam lugar especial reservado no ordenamento jurídico, qual seja, acima das leis infraconstitucionais.
} 


\section{[...] a verdade é que de modo inconsciente o Supremo Tribunal Federal consagrou a correta tese da constitucionalidade dos tratados internacionais sobre direitos humanos, quer tenha sido aprovados como emenda, quer não tenham sido; tese que tem respaldo no $\S 2^{\circ}$ do Art. $5^{\circ}$ da Constituição Federal de 1988. (CARVALHO, 2013, p. 149, grifo nosso).}

Feliciano de Carvalho (2013) destaca ainda que se a norma supralegal paralisa os efeitos da legislação infraconstitucional, em regra, somente emendas à Constituição poderiam alterar ou suprimir as normas supralegais. Isso ocorreria, apenas, em regra, porque nem mesmo as emendas teriam autorização do Constituinte originário para suprimir direitos humanos ou fundamentais, sob pena de negar vigência aos princípios basilares do Estado Democrático de Direito.

A título dedutivo, percebe-se que, se as normas supralegais são constitucionais, estas não podem sofrer alteração ou serem suprimidas pela legislação comum, nem mesmo por emenda à Constituição, já que, ao consagrarem direitos considerados pela Carta Magna como cláusulas pétreas, não podem também ser abolidas. Esse entendimento é corroborado pela interpretação correlata do que dispõe o texto constitucional brasileiro, em seu art. $1^{\circ}$, III, ao consagrar a dignidade da pessoa humana como fundamento da República Federativa do Brasil; art. $4^{\circ}$, II, ao dar prevalência aos direitos humanos nas relações internacionais; art. $5^{\circ}, \S 2^{\circ}$, ao conceber a existência de direitos humanos e fundamentais, ainda que não estejam expressos no texto constitucional (TESTA; CENCI, 2014).

Aliás, importante destacar que, mesmo atribuindo o status de supralegalidade a estas normas internacionais, é preciso considerar a aplicabilidade do princípio da norma mais favorável - pro homine - e da proibição do retrocesso social no direito internacional de direitos humanos.

Destarte, no caso de conflito, as normas de direitos humanos, com o fim de atender ao princípio pro homine, irão prevalecer sobre as normas constitucionais, pois segundo Sarlet (2012), entendimento diverso acarretaria verdadeiro retrocesso social.

Afinal, é vedado o retrocesso quando a temática envolve direitos fundamentais. Para Sarlet (2012), a proibição resulta diretamente do princípio da maximização da proteção de todos os direitos dos direitos fundamentais, impondo não somente ao poder constituinte reformador, mas também ao legislador ordinário e demais órgãos estatais e internacionais, o dever permanente de desenvolvimento e concretização eficiente dos direitos fundamentais. 
Nesta perspectiva, Weis (2010) observou que as hierarquias normativas são apenas construções teórico-jurídicas dos Estados e não podem servir de óbice ao reconhecimento e à aplicação de direitos fundamentais, seja qual for o veículo normativo em que estejam previstos. Assim, aplicar-se-á sempre a norma mais favorável, independentemente se advinda da ordem jurídica interna ou internacional.

A busca pela efetividade de um direito internacional, no âmbito das relações de trabalho, propagada por uma instituição de garantia, reclama a superioridade do direito internacional e a maior hierarquia das declarações e os direitos humanos como parte do jus cogens, isto é, norma imperativa, com o surgimento de um direito universal dos direitos humanos.

Referida interpretação conduz ao entendimento de que, em havendo conflito entre uma convenção internacional do trabalho ratificada e as leis internas nacionais, a prevalência será por aquela em que se apresentar mais favorável à proteção dos direitos fundamentais, em homenagem ao princípio pro homine. Mazzuoli (2013b) observa que se um dos propósitos da OIT é a universalização das regras trabalhistas, não seria razoável para o trabalhador que eventuais normas das convenções adotadas pela Organização fossem menos favoráveis em relação às normas do Direito interno de seu país. Tal raciocínio tem respaldo no $\S 8^{\circ}$ do art. 19 da Constituição da OIT, ao dispor expressamente que (ORGANIZAÇÃO INTERNACIONAL DO TRABALHO, 1946, grifo nosso):

Em caso algum, a adoção, pela Conferência, de uma convenção ou recomendação, ou a ratificação, por um Estado-membro, de uma convenção, deverão ser consideradas como afetando qualquer lei, sentença, costumes ou acordos que assegurem aos trabalhadores interessados condições mais favoráveis que as previstas pela convenção ou recomendação.

A cláusula supracitada pode ser chamada de "cláusula de diálogo" ou "vaso comunicante", destaca Mazuolli (2013b), entre o direito internacional dos direitos humanos e outras normas de proteção. Tais cláusulas são aquelas, presentes nos tratados de direitos humanos, cuja função é promover a interligação entre a ordem jurídica internacional com a ordem interna dos Estados nacionais, de tal modo que não haja prevalência de um ordenamento sobre o outro, mas sim diálogo entre eles.

O art. $19, \S 8^{\circ}$, da Constituição da OIT, é exemplo de cláusula de diálogo especial, pois não se refere exclusivamente às leis, ao dispor também sobre as 
sentenças, costumes ou acordos que possam assegurar condições mais benéficas aos trabalhadores, em comparação ao disposto em convenções e recomendações da OIT (MAZZUOLI, 2013b, p. 85-6, grifo nosso):

Daí a possibilidade de uma norma jurídica interna - assim como uma sentença, ou um costume ou eventual acordo - ser aplicada em detrimento do estabelecido por uma convenção ou recomendação internacional do trabalho, uma vez que o princípio adotado pela OIT nãoé a primazia das normas internacionais do trabalho sobre o Direito interno estatal, mas a prevalência da norma mais favorável ao trabalhador.

Isso significa que a opção será sempre pela aplicação da norma que, no caso concreto, mais proteja os interesses da pessoa. O sentido e o conteúdo do princípio pro homine é exatamente esse: abrir as possibilidades para o julgador e o intérprete do direito aplicar com mais justiça no caso concreto, atendendo ao fim social que o direito do trabalho e os direitos humanos reclamam.

Outros princípios a serem difundidos pela OIT e que devem ser observados, tanto na elaboração de novas normas, como também na apreciação e julgamento dos casos ora submetidos, seriam: a) princípio da observância do minimum core obligation; $b$ ) princípio da aplicação progressiva, do qual decorre o princípio da proibição do retrocesso social.

Piovesan observa que o estudo dos relatórios do Comitê de Direitos Econômicos, Sociais e Culturais da ONU permite revelar que tais princípios são importantes em matéria de direitos sociais. A respeito do primeiro princípio, a autora salienta que (PIOVESAN, 2010, p. 21): "A jurisprudência internacional [...] tem endossado o dever dos Estados de observar um minimum core obligation no tocante aos direitos sociais [...]".

No que se refere ao segundo princípio - aplicação progressiva e da proibição do retrocesso social - Piovesan (2010) ressalta que cabe aos Estados nacionais, de acordo com o Comentário Geral n 3 do Comitê, adotar medidas por meio de ações concentradas, de modo mais efetivo possível, voltadas à implantação dos direitos sociais: "Note-se que há medidas de aplicação imediata concernente aos direitos sociais, como é o caso da cláusula da proibição da discriminação" (PIOVESAN, 2010, p. 22).

Tais princípios são condizentes com o estabelecimento e respeito a direitos básicos trabalhistas universais que possam garantir o padrão civilizatório mínimo com o fim de resguardar a dignidade do trabalhador. 
Assim, a OIT poderia criar programas e políticas direcionadas ao reforço e promoção dos princípios aqui aduzidos, pois, em pese sejam princípios do direito internacional, previstos, inclusive, em convenções da OIT, muitas vezes os Estados, a exemplo do Brasil, repelem a sua aplicação, ao criar teses como o da supralegalidade.

\section{CONSIDERAÇÕES FINAIS}

As consequências da globalização não se fizeram sentir apenas em relação ao Estado, tendo impactos profundos sobre as relações de trabalho. A integração dos mercados, a existência de empresas transnacionais e a concorrência acirrada destas acabaram por tornar mais complexas as relações laborais, e levaram a uma fragmentação do modo de produção e do aumento da precarização do trabalho.

O domínio tecnológico e o fenômeno da globalização da economia são irreversíveis e, num mundo globalizado, os países e suas economias estão interligados, de tal modo que as relações laborais merecem proteção advinda de regras universalmente impostas, já que aplicar apenas o ordenamento jurídico interno não traria muitos resultados. Essa realidade reclama a existência de padrões mínimos universais a serem aplicados nas relações de trabalho, e o reconhecimento de certos direitos trabalhistas como direitos humanos universais.

Diversos documentos internacionais, à luz da dignidade da pessoa humana e da ideia de trabalho decente propagada internacionalmente, permitiram concluir que há, atualmente, um rol de direitos do trabalho universalmente reconhecidos, sob o status de direitos humanos.

Não basta, todavia, normatizar direitos que garantam o padrão mínimo civilizatório, é necessário que haja uma instituição capaz de efetivá-los na comunidade internacional/transnacional.

Embora a Organização Internacional do Trabalho tenha cumprido tal papel, se faz necessário avançar na função desta Organização. Assim, este ensaio buscou demonstrar, ao fazer alguns apontamentos que poderiam representar avanços na OIT, por meio de políticas a serem realizadas internamente na instituição, e outras a serem concretizadas no âmbito externo, juntamente aos Estados-membros.

A intenção primordial foi o de refletir sobre um processo de melhoria da Organização Internacional do Trabalho, de tal modo que essa instituição seja capaz de lidar com os efeitos prejudiciais da globalização econômica nas questões 
sociais, ao representar uma instituição de garantia transnacional, apta a regulamentar, fiscalizar e efetivar regras mínimas universais em matéria trabalhista; por meio de sistema eficaz de controle e monitoramento, destinado a contribuir para o desenvolvimento do direito internacional rumo à construção de uma comunidade universal constituída por relações jurídicas transnacionais.

\section{REFERÊNCIAS}

AMARAL JÚNIOR, Alberto. Cláusula social: um tema de debate. Revista de Informação Legislativa, Brasília, ano 36, n. 141, p. 129-141, jan./mar. 1999. Disponível em: <http://www2.senado.leg.br/bdsf/bitstream/handle/id/ 456/r141-11.pdf?sequence=4>. Acesso em: 29 jun. 2015.

\section{BARROSO, Luís Roberto. Curso de direito constitucional} contemporâneo: os conceitos fundamentais e a construção do novo modelo. 4. ed. São Paulo: Saraiva, 2013.

BELTRAN, Ari Possidonio. Os impactos da integração econômica no direito do trabalho: globalização e direitos sociais. São Paulo: LTr, 1998.

CARVALHO, Feliciano de. A natureza jurídica constitucional de todos os tratados internacionais de direitos humanos: análise da supralegalidade e da inconsciência do Supremo Tribunal Federal brasileiro. In: DEL OLMO, Florisbal; GUIMARAES, Antonio Márcio C.; CARDIN, Valéria S. G. (Coord.). Direito internacional dos direitos humanos I. Florianópolis: FUNJAB, 2013. p. 137-157.

CRIVELLI, Ericson. Direito internacional do trabalho contemporâneo. São Paulo: LTr, 2010.

DELGADO, Maurício Godinho. Curso de direito do trabalho. 14. ed. São Paulo: LTr, 2015.

FARIA, Eduardo. Democracia e governabilidade: os direitos humanos à luz da globalização econômica. In: FARIA, José Eduardo (Org.). Direito e globalização econômica: implicações e perspectivas. São Paulo: Malheiros Editores, 2010. p. 127-160. 
FERRAJOLI, Luigi. Democracia, estado de derecho y jurisdicción em la crisis del Estado Nacional. In: FERRAJOLI, Luigi; ATIENZA, Manuel. Jurisdicción y argumentación em el estado constitucional de derecho. México: Instituto de Investigaciones Jurídicas, 2005. p. 109-133.

JEAMMAUD, Antoine. A internacionalização do trabalho: os novos desafios da integração econômica. In: JEAMMAUD, Antoine et al. Trabalho, cidadania \& magistratura. Rio de Janeiro: Edições Trabalhistas, 2000, p. 75-92.

LIMA NETO, Arnor. A proteção contra a despedida arbitrária ou sem justa causa do trabalhador brasileiro no contexto dos direitos fundamentais e sua efetividade. In: HASSON, Roland (Org.). Direito dos trabalhadores \& direitos fundamentais. Curitiba: Juruá, 2003.

MAHNKOPF, Birgit. O futuro do trabalho: globalização da insegurança. In: PETERSON, Nikolai; SOUZA, Draiton Gonzaga (Org.). Globalização e justiça II. Porto Alegre: EDIPUCRS, 2005. p. 47-68.

MAZZUOLI, Valério de Oliveira. Curso de direito internacional público. 7. ed. São Paulo: Revista dos Tribunais, 2013a.

MAZZUOLI, Valério de Oliveira. Integração das convenções e recomendações internacionais da OIT no Brasil e sua aplicação sob a perspectiva do princípio pro homine. Revista do Tribunal Regional do Trabalho da 15 ${ }^{\text {a }}$ Região, Campinas, n. 43, p. 71-92, 2013 b.

MOREIRA, Eduardo Ribeiro. Por um constitucionalismo global. Revista de Direito Constitucional e Internacional, São Paulo, ano 18, n. 73, p. 102116, out./dez. 2010.

NASCIMENTO, Amauri Mascaro. Iniciação ao direito do trabalho. 38. ed. São Paulo: LTr, 2013.

ORGANIZAÇÃO DAS NAÇÕES UNIDAS - ONU. Declaração universal de direitos humanos. 1948. Disponível em: <http://unicrio.org.br/ img/DeclU_D_HumanosVersoInternet.pdf>. Acesso em: 25 abr. 2015. 
ORGANIZAÇÃO INTERNACIONAL DO TRABALHO - OIT. Constituição e seu anexo: Declaração De Filadélfia. 1946. Disponível em:<http://www.oitbrasil.org.br/sites/default/files/topic/decent_work/doc/ constituicao_oit_538.pdf $>$. Acesso em: 20 abr. 2015.

ORGANIZAÇÃO INTERNACIONAL DO TRABALHO - OIT.

Convenção 158. 1985. Disponível em: <http://www.conjur.com.br/dl/ convencao-oit-158.pdf>. Acesso em: 1 maio 2015.

ORGANIZAÇÃO INTERNACIONAL DO TRABALHO - OIT. Declaração relativa aos direitos e princípios fundamentais no trabalho. 1998. Disponível em: < http://www.oitbrasil.org.br/sites/default/ files/topic/oit/doc/declaracao_oit_547.pdf>. Acesso em: 27 abr. 2015.

PIDESC. Pacto Internacional de Direitos Econômicos, Sociais e Políticos. 16 de dezembro de 1966. Disponível em: <http://bvsms.saude.gov.br/bvs/ publicacoes/pacto_internacional_direitos_economicos_sociais_ culturais.pdf>. Acesso em: 27 abr. 2015.

PIOVESAN, Flávia. Direito ao trabalho e a proteção dos direitos sociais nos planos internacional e constitucional. In: PIOVESAN, Flávia; CARVALHO, Luciana Paula Vaz (Coord.). Direitos humanos e direito do trabalho. São Paulo: Atlas, 2010. p. 3-31.

PIOVESAN, Flávia. Direitos humanos e o direito constitucional internacional. 13. ed. São Paulo: Saraiva, 2012.

ROMITA, Arion Sayão. Direitos fundamentais nas relações de trabalho. 5. ed. São Paulo: LTr, 2013.

SARLET, Ingo Wolfgang. A eficácia dos direitos fundamentais: uma teoria geral dos direitos fundamentais na perspectiva constitucional. 11. ed. Porto Alegre: Livraria do Advogado, 2012.

SÜSSEKIND, Arnaldo. Direito constitucional do trabalho. 3. ed. Rio de Janeiro: Renovar, 2004. 
TESTA, Janaina Vargas; CENCI, Elve Miguel. O transconstitucionalismo e a supraconstitucionalidade dos tratados de direitos humanos como propostas para a prevalência dos direitos humanos e a humanização do direito. In: CONGRESSO NACIONAL DO CONPEDI, 23., 2014, Florianópolis. Anais... Florianópolis: CONPEDI, 2014. p. 418-442.

TRINDADE, Antônio Augusto Cançado. Tratado de direito internacional de direitos humanos. Porto Alegre: Sérgio Antônio Fabris, 2003.

WEIS, Carlos. Direitos humanos contemporâneos. 2. ed. São Paulo: Malheiros Editores, 2010.

Submetido em 09/10/2015 Aprovado em 21/11/2015

Como citar: CENCI, Elve Miguel; TESTA, Janaina Vargas. Universalização de direitos trabalhistas: uma proposta de avanço no papel da Organização Internacional do Trabalho. Scientia Iuris, Londrina, v.19, n.2, p.155-180, dez.2015. DOI: 10.5433/2178-8189.2015v19n2p155. ISSN 2178-8189. 